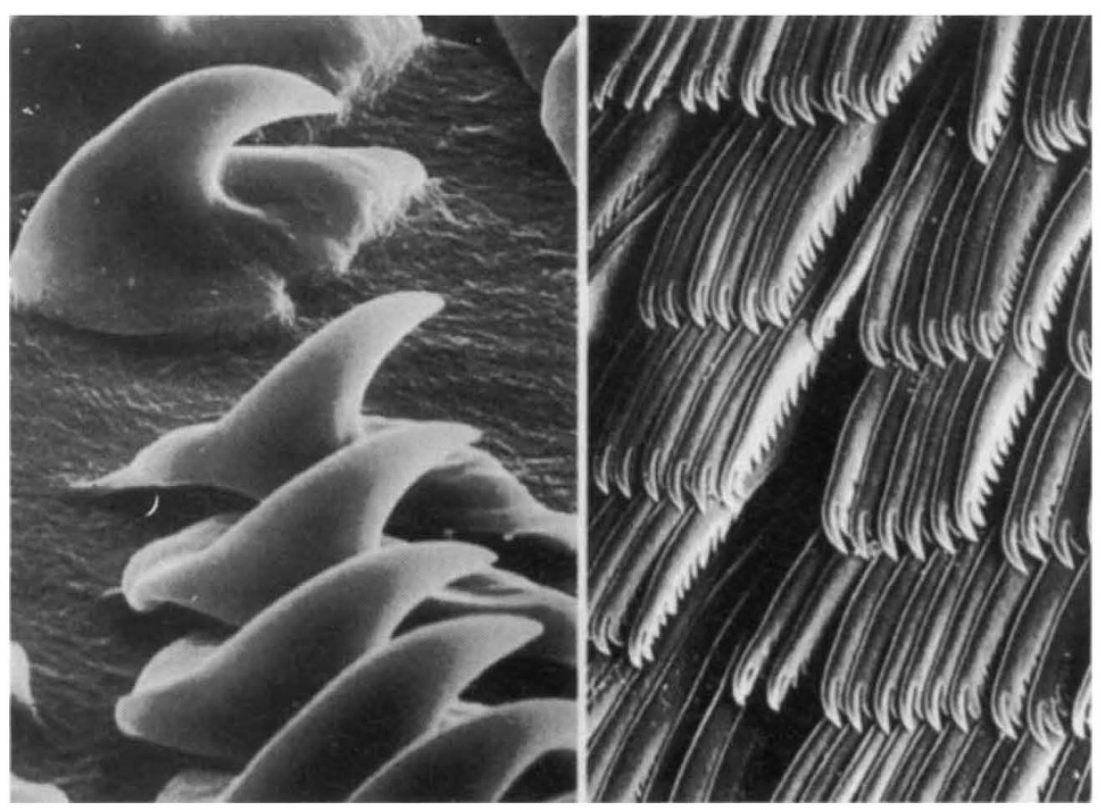

THE cutting edge - chitinous teeth of the radula, the unique tongue-like feeding organ of molluscs that works in much the same way as a rasp and conveyor belt. The teeth displayed here are from the marine gastropods Berthella stellata (left, $x$

$\sim 30,400$ ) and Berthellina citrina (right, $\times \sim 4,000$ ). From Microscopic Anatomy of Invertebrates, Vol. 5: Mollusca I edited by F. W. Harrison and A. J. Kohn (Wiley, \$213, £152).

\section{An American tale}

\section{Stuart L. Pimm}

A History of the Ecosystem Concept in Ecology: More than the Sum of the Parts. By Frank Benjamin Golley. Yale University Press: 1993. Pp. 254. £25, \$30.

I was once denied a grant because I was "not an ecosystem ecologist". Frank Golley tells me why: I am the wrong nationality. Despite the British invention of 'ecosystem' and its first-place ranking among concepts by contemporary British ecologists, "the ecosystem story is largely an American tale". Golley tells how ecologists with a common language have trodden separate paths from the start.

Golley is in a unique position to do this. $\mathrm{He}$ and his colleagues in Georgia have been key players in ecology for nearly 40 years, but friendships and personal investment have not produced an eulogy. The book's strength is its detached evaluation of researchers and some of ecology's largest research programmes. Readers will find an excellent account of how crucial ideas developed and will ponder how much a lifetime's work can accomplish.

The history begins with Arthur Tansely, who coined the term 'ecosystem' in 1935 , and his discussions with John Phillips; moves on to Raymond Lindeman, the brothers Odum, the International Biological Program (IBP)'s "Analysis of Ecosystems" project and George van Dyne; and finishes at the end of the 1970s.

The tale becomes a largely American one with Lindeman. The initial rejection in 1941 of his paper "The trophic dynamic aspect of ecology" is a familiar story. One reviewer (probably Chancey Juday, a distinguished limnologist of the day) wrote: "[most of] the ... discussion and argument is based on belief, probability, possibility, assumption, and imaginary lakes, rather than on actual observation and data." That comment was prescient. Sadly, Golley does not contrast Lindeman's concerns with those of contemporary British ecologists. They too were grappling with the ecology of things more complex than populations. At a meeting in 1944, Charles Elton was counting the number of species per genus in plant and animal communities and David Lack was measuring beak dimensions of Darwin's finches.

Golley writes of the next two decades: "that the ecosystem concepts were not presented as hypotheses to be tested or questions to be asked was the most serious weakness ... of this period". Observations test hypotheses. Yet observations were no more in evidence in 1965 than when Lindeman's paper was rejected in 1941. Up to here, the middle of the book, there are only two graphs or tables with numbers in them (one is Golley's, the other Juday's). An example of this ecologists' never-never land is Eugene Odum's assertion in 1959 that as ecosystems developed over time they would become dynamically stable. One could explore this hypothesis through both computer modelling and empirical testing. In fact,
Odum stated his idea as a principle and not a hypothesis, which inhibited testing. A Brookhaven workshop in 1969 explored the principle and found it wanting. In neither Odum's proposal nor the meeting's proceedings is there a single graph or table of empirical or theoretical results with stability on one axis and time (or anything else) on the other.

The IBP was to change all this. How quickly it lost direction! Initial ideas stressed the measurement of "organic production and decomposition at different trophic levels". In 1965, Eugene Odum chaired the terrestrial productivity group. The themes developed in cooperation with the freshwater group were production, trophic structure, energy flow, nutrient cycling and the like on a planetary scale. By 1967, American modellers had taken over and the language was "driving forces", "components" and "coupling". The grassland model was ELM - for Intermediate Level Model. Neither the inability to spell nor the awful pun in the naming of this model of a treeless system humoured the field biologists. We lowly graduate students were charged with collecting the data to validate (not test) the models. Favoured faculty members studied the few processes that the modellers did not fully understand. The model was supreme and its triumphant presentation on the last day of each annual meeting was our reward. By 1974, a new catch-phrase buzzed in the Fort Collins bars on the first evening: "non-modelling synthesis". The data, their synthesis and analysis might be interesting in their own right. Golley's evaluation of the IBP is short, honest and brutal. He does not tell us that for a long time after the IBP, the only accessible compilations of data on ecosystems were those compiled before the project.

Golley's final thoughts are also interesting, for his story provides the grist for a powerful mill: comparative science. The developments in other countries tell us much about why they followed different paths. Elsewhere, he correctly emphasizes how the desire for clear hypotheses and their testing through experiment and observation led researchers away from ecosystem studies. Golley also suggests a British disdain for large research teams and their delight in the individual project. More crucially, he makes a compelling case for the need for the comparative data that only large teams can provide. Ecosystem ecology for too long has operated in a dream world with few hypotheses and even fewer data. The clear lessons from this book are that for ecosystems we will win neither the hypotheses nor the data easily.

Stuart L. Pimm is in the Department of Zoology and Graduate Program in Ecology, University of Tennessee, Knoxville, Tennessee 37996, USA 